\title{
PESTRON FOR QUALITY MONITORING OF CUSTARD APPLES
} \author{
S. VIJAYACHITRA ${ }^{1}$, E. HARIPRASHANNA ${ }^{2}$, S. HARIPRIYA ${ }^{3}$, V.S. KAVIN ${ }^{4} \&$ P. MOHAN RANJITH ${ }^{5}$ \\ ${ }^{1}$ Professor, Department of Electronics and Instrumentation Engineering, Kongu Engineering College, Perundurai, India \\ ${ }^{2,3,4,5}$ UG Scholars, Department of Electronics and Instrumentation Engineering, Kongu Engineering College, Perundurai, India
}

ABSTRACT
Fruit quality is an important parameter in the food processing industries. It is necessary to analyze external
characteristics of the fruit sample and treat the fruit samples. Under natural illumination, the fruit samples are analyzed
with designed Algorithm. Ultimately, this algorithm is intended to enable estimation of the custard apple quality. The
algorithm includes main steps: extraction of pixels that has high possibility of detecting pests (White), using color and
smoothness. Comparison of the processed image with a standard model of a custard apple will detect the percentage of
disorder. The algorithm detects $90 \%$ of Defect custard apples visible in the images. In accordance to the Percentage of
Disorder analyzed, fruit sample is subjected to treatment. This method could reduce the consumption of water and
provides efficient way for washing fruit samples. Since it can act as Pesticide to treat the fruit as a quality oriented along
with Electronics, the proposed proto type is named as PESTRON.
KEYWORDS: Weight, Image Processing, Load Cell, Graphical User Interface, PESTRON

Received: Jun 06, 2020; Accepted: Jun 26, 2020; Published: Aug 07, 2020; Paper Id.: IJMPERDJUN2020678

\section{INTRODUCTION}

Fruit quality is that the quality characteristics of fruit which is acceptable to consumers. Fruits and vegetables are increasing in popularity within the daily diets of individuals of both developed and developing countries. The selections concerning harvesting, maturity, ripeness and quality are based on subjective and visual inspection of the fruit's external appearance. Fruit Import and Export plays an important role in economic process of company. There is a need for washing fruit and quality analysis. Now-a-days, there is a lack of automation in washing the Fruits and conventional existing methods are most costly. Hence it is essential to seek a solution to solve the above problems.

Consumption of Custard apples have given many benefits such as the availability of anti-oxidants like Vitamin C, which further helps to provide immunity over free radicals in our body. It has more potassium and magnesium which helps to protects our heart from cardiac disease and also controls our blood pressure. They contain Vitamin A, which keeps the body skin and hair healthier.

Under dry weather climatic condition, attack of mealy bug in custard apples is more and looks white colored fungus over the fruit surface. The following Figure.1 shows such case found in custard apples. 


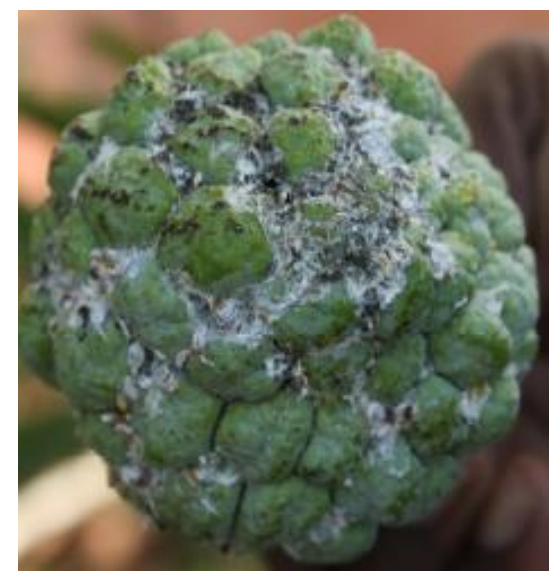

Figure 1: Mealy Bug Infected Custard Apple.

Since it can act as Pesticide to treat the fruit as a quality oriented along with Electronics, the proposed proto type is named as PESTRON.

\section{COMPUTER VISION BASED ANALYSIS}

To improve the Export activities of custard apples and to provide better quality oriented fruits, it is preferred to do computer vision based analysis.

\section{Review Stage}

The computer vision strategies can be used to recognize the quality of fruits which rely on four basic features characterize the object such as intensity, color, shape and texture of the fruits under testing. The term quality implies the degree of excellence of a product or its suitability for a specific purpose. Quality of produce encompasses sensory properties like appearance, texture, taste and aroma, and mechanical properties, chemical constituents, nutritive values, functional properties and defects. Product quality evaluation methods are naturally extremely important. Quality evaluation of fruits and vegetables are often of destructive and nondestructive types. In the former the whole fruit is destroyed while evaluating the standard. In nondestructive quality evaluation, the fruits and vegetables aren't destroyed while evaluating its quality. Non destructive methods are preferably used for analyzing the quality of the fresh fruits and vegetables. There are several techniques used under non destructive quality checking include mechanical type, optical type and electromagnetic type techniques.

To monitor and maintain the fruit's quality, it is very much essential to measure quality oriented attributes which include sensor characteristics, nutrition related attributes, chemical compositions, mechanical characteristics and other functional properties. Measurements by suitable instruments are often utilized for sensory evaluations and many commercial situations in industrial applications. Basically, electromagnetic and optical properties relate to physical appearance, mechanical properties related to surface texture and chemical properties towards flavor such as taste and aroma. Instruments are used for measuring the fundamental properties to categorize the fruit's quality or standard by means of monitoring the quality-related attributes, which are necessary for inspection and further research.

\section{Proposed System}

This proposed system is used for monitoring and measuring the quality of the custard apples by the application of image processing technique. The proposed methodology includes the following major steps. 
- Determination of pixels that have a high probability using color and smoothness of custard apples

- Development and extending the seed areas, which are connected sets of pixels that have a high probability of belonging to custard apples

- Segmentation of various contours of those seed areas into arcs and amorphous segments and

- Combination of these arcs and comparing the resulting circle with a simple model of the custard apple

It is investigated the performance of the algorithm by using two kinds of datasets. The dataset -1 consists of images which are recorded under various lighting conditions. Even though the proposed algorithm can detect the quality as $85 \%$ goodness in the images, direct illumination and color saturation cause more number of false positive detections as bad quality fruits. The dataset- 2 consists of images which are manually recorded under mostly diffusive lighting condition. For such images in dataset-2, true positive detection rate is closer to $95 \%$ and the false positive detection rate is less than $5 \%$.

\section{Image Processing of Fruit Quality Analysis}

The quality analysis of custard apples involves three sections such as weighing of fruit samples, color sensing and checking the presence of mealy bugs in the fruit sample by using image processing techniques. A block diagram as shown in Figure. 2 represents the process flow involved in the proposed system.

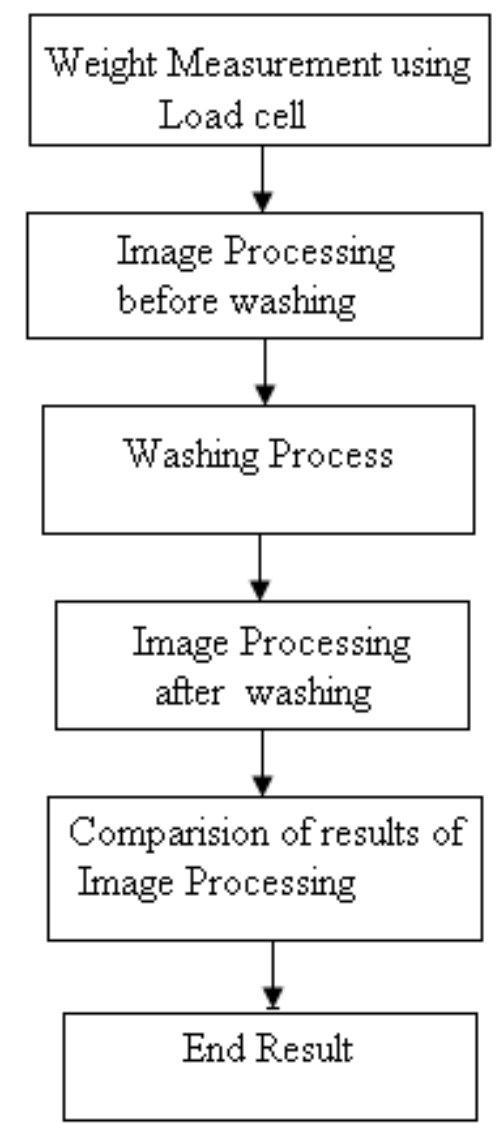

Figure 2: Block Diagram of Fruit Quality Analysis. 
The color value of the presence of Melay bugs over the custard apple is extracted from the sample image fed to the algorithm. The color range is then fixed according to the value obtained from the sample image. Then capturing of the image of the custard apple from different sides is recommended for the better results. For this purpose, the base from the developed instrumental system holds the fruit is motor driven and it can rotate based on the delay time specified in Arduino sensor.

Simultaneously, the algorithm checks whether the read value lies in the range of the color value read from the sample image of the bug. If color value matches, a count value gets incremented. Then the Process is repeated for all the four images and the first cumulative count value named count_value_before_wash will be available at the end of the process analysis. The same process is repeated after the washing and the second cumulative named count_value_after_wash value is further obtained.

Next, a comparison is made between the two cumulative values obtained earlier to obtain the end result. The result shows whether the washing is effective or ineffective to get the bug free fruits finally and proper decisions are taken accordingly. If it is found that the result is ineffective, the washing process is to be performed again to get complete bug free fruit. From the proposed algorithm, the result window appears after all the above process is proportional to the change in dielectric value

\section{Weight Based Fruit Quality Analysis}

Load cell is weight measuring sensor which produces the output in analog form. It needs signal conditioning unit like HX711. Load cell and signal conditioner are connected using four wires such as Red, Black, White and Green/Blue. The connection details followed is given below.

- RED Wire is connected to E+

- BLACK Wire is connected to E-

- WHITE Wire is connected to A-

- GREEN Wire is connected to A+

In this process, Arduino sensor is used to control the entire process. Weight of the sample fruit is sensed by Load cell sensor and generated analog voltage which is transmitted to HX711 Amplifier circuit in the proposed model. HX711 is a 24bit ADC, which amplifies and digitally converters the Load cell output. Signal conditioned voltage signal is further fed to Arduino controller and the calculated output of HX711 is converted in terms of grams of the sample fruit. Figure.3 shows the load cell connection with Arduino Sensor.

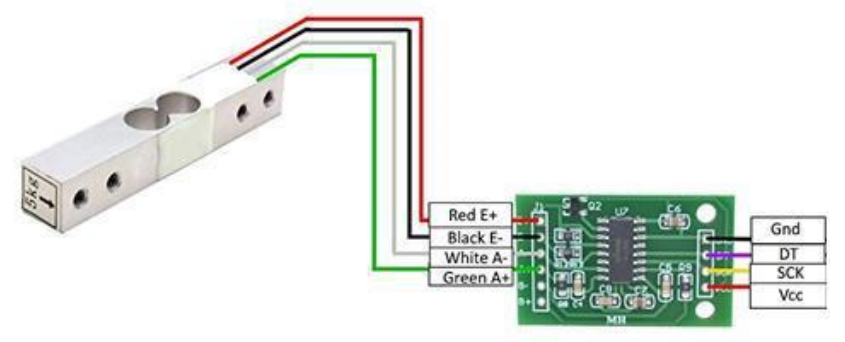

Figure 3: Load Cell Connection with Arduino Sensor. 


\section{Work Flow of PESTRON}

A Graphical User Interface (GUI) is developed for better understanding of the concept behind the working of PESTRON. When the "design of PESTRON" button is clicked, the window popups shows the design aspect and the parts involved in the PESTRON for the better understanding of the concept. Figure.4 gives the working of PESTRON and GUI.

The First step is to measure the weight of the fruit using the load cell. The maximum capacity of the Load cell used in the model is about $5 \mathrm{~kg}$ and by using this sensor, the weight of the sample fruit can be recorded continuously. The data can be utilized at the time of packing. The image of the fruit is first captured by the camera and fed to the computer for further processing. The image processing algorithm determines the intensity of bug present in the custard apple. After the steps of image processing, the fruit is carried to the conveyer through a slider. The conveyer is further attached with the washing arrangements in order to remove the bugs to the maximum extend. The water is sprayed on the three sides for an effective washing of the fruit samples.

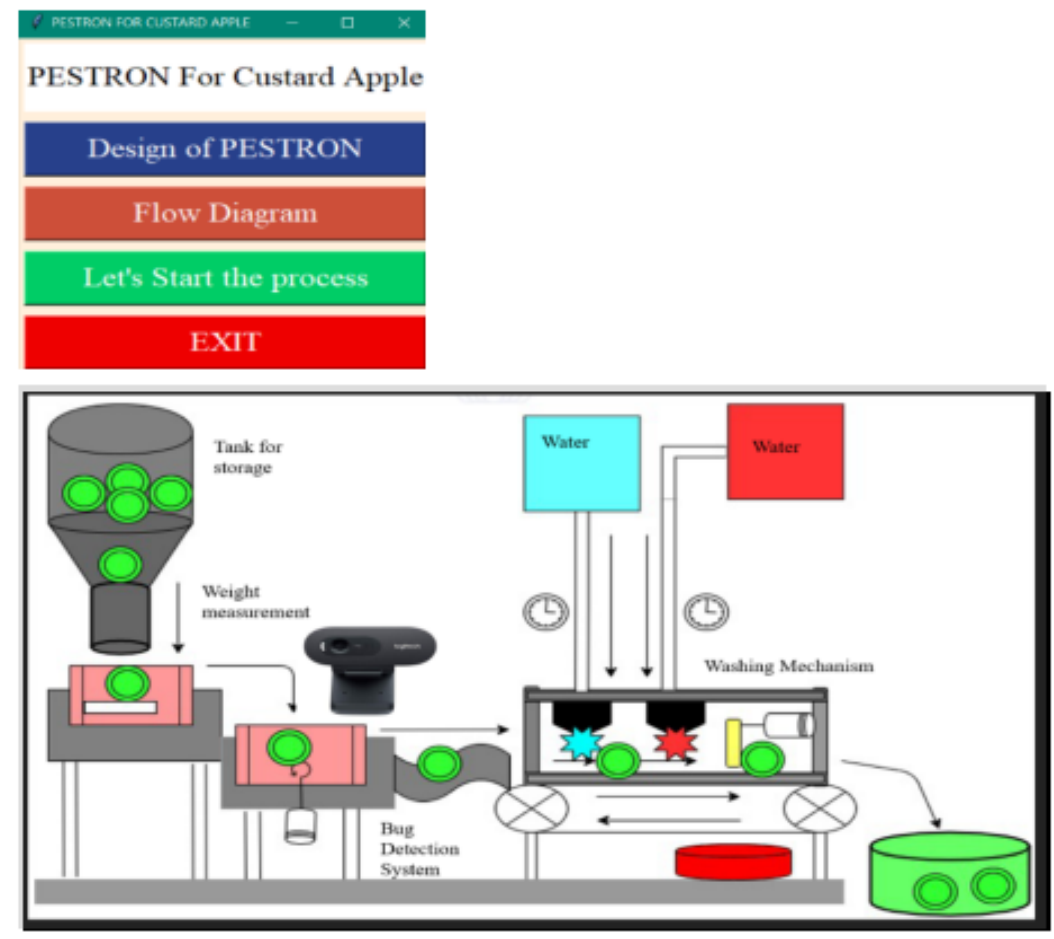

Figure 4: Working of PESTRON and GUI.

When the washing process is over, the image of the fruit is again captured and the sent to the system for processing. The STEP-2 is repeated here and then the result is recorded and the fruit moves to the container. After all the above four processes are over, the end result of the STEP-2 and STEP-4 are compared. The result of the comparison shows whether the washing is effective or not and a decision is taken according to the result. The following Table- 1 shows the weight based decision making for fruit quality analysis. 
Table 1: Weight Based Decision Making for Fruit Quality Analysis

\begin{tabular}{|c|c|l|}
\hline Sample & Weight $(\mathbf{g m})$ & \multicolumn{1}{|c|}{ Decision } \\
\hline 1 & 73.06 & Bad Sample \\
\hline 2 & 73.08 & Bad Sample \\
\hline 3 & 74.02 & Bad Sample \\
\hline 4 & 74.08 & Bad Sample \\
\hline 5 & 76.00 & Bad Sample \\
\hline 6 & 105.92 & Good Sample \\
\hline 7 & 105.92 & Good Sample \\
\hline 8 & 110.20 & Good Sample \\
\hline 9 & 150.00 & Good Sample \\
\hline 10 & 180.20 & Good Sample \\
\hline
\end{tabular}

Figure. 5 shows the steps carried out in image processing of sample fruit.

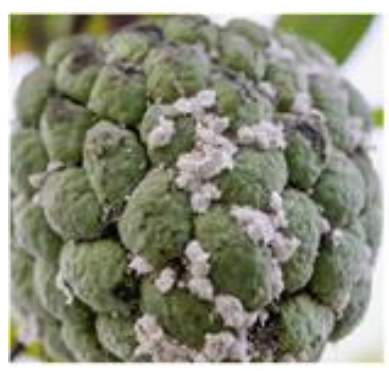

(a) Sample RGB Image

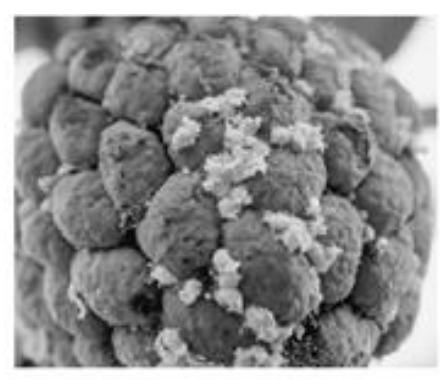

(b) Sample- Grey Image

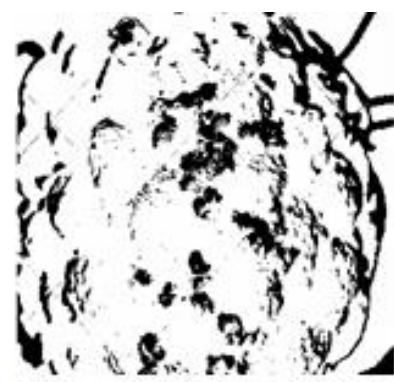

(c) Final Output- Bug extracted

Figure 5: Steps Carried Out in Image Processing of Sample Fruit.

\section{PROTOTYPE MODEL DEVELOPMENT}

The following Fig. 5 shows the developed prototype model for the purpose of the fruit quality analysis of the custard apples arranged in the conveyor.

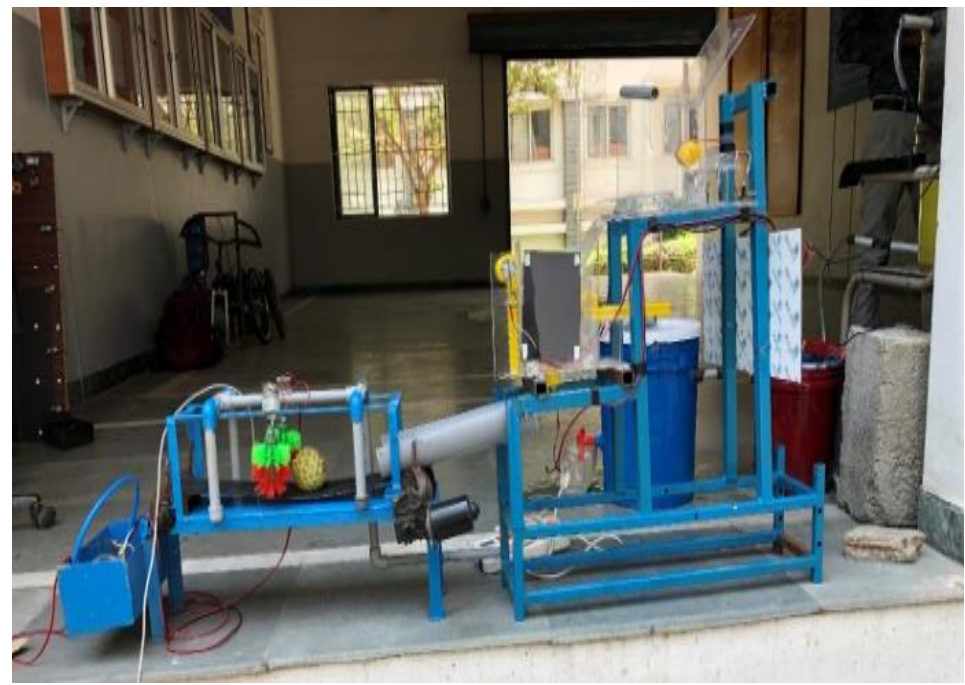

Figure 6: Prototype Model Development.

\section{DESIGN IMPLEMENTATION}

Image processing involves the determination of HSV value and volume of the samples. Load cell measures the weight for the sample and if any deviation is found from the standard permissible weight values, it will be considered as a defective 
sample and it could also be transmitted for cloud analysis. Then the Back Propagation Neural Network is used to determine the quality in more number of the fruit samples. It is found that, by the proposed method, it would be possible to analyze the presence of bugs in fruit samples and thereby the quality of them can also be determined effectively.

In addition, weight of the fruit samples is measured with load cell and HSV value determines the Brown pigment which further determines the ripening stage of the custard apples. Then the output voltage is given to Arduino controller. Based on the HSV value and weight value, the quality of the fruits can be determined effectively.

\section{CONCLUSIONS}

The developed prototype is modular and can be customized based on the industry requirements. The existing solutions were more costly which makes the solutions highly inaccessible by the small scale industries. Hence the proposed model can be more suitable for the small scale industries. This method could be applied for Agri export industries. It could measure more samples and it can reduce labor cost. It also ensures the lifetime of fruit samples under analysis. Stabilized market sale is assured by this methodology and proto type model which further can improve Export rate and stabilize the variation in price rate irrespective of climatic conditions.

\section{REFERENCES}

1. R. Maruthadurai and V. Karuppaiah, "Managing Menace of Insect Pests on Custard Apple”, Popular Kheti, Vol-2, Issue-3, (2014), pp-108-111.

2. S. Sijayachitra, “Transducers Engineering”, Prentice Hall of India, New Delhi, (2016).

3. Reddy, T. Raja, E. Lokanadha Reddy, and T. Narayana Reddy. "Ethical Issues in Advertising to Children-A Kantian Perspective." International Journal of Sales \& Marketing Management Research and Development (IJSMMRD) 6.1, Feb $2016,17-24$

4. S. Vijayachitra, E.Hariprasanna.,S.Haripriya. V.S.Kavin. and P.Mohan Ranjith, "Non-Invasive Fruit Analyser_1.7”, International Journal of Innovative Technology and Exploring Engineering (IJITEE), Vol.-9 Issue-2, (2020). pp-1567-1570.

5. Panda, Sujogya Kumar. "Screening methods in the study of antimicrobial properties of medicinal plants." International Journal of Biotechnology and Research 2.1 (2012): 1-35.

6. Lakshmi S., A.K.Pandey, N.Ravi, O.P.Chauhan, Natarajan Gopalan and R.K.Sharma Defective Food Research Laboratory, Mysuru-570011, India

7. Afsar MN, Birch JR, Clarke RN, Chantry GW, “,Measurement of dielectric properties of materials. IEEE Trans Instrum Meas Vol.74, No.1, (1986), pp.183-199.

8. Ahmed J, Ramaswamy HS, Raghavan VGS, "Dielectric properties of soybean protein isolates dispersions as a function of concentration, temperature and pH”, Journal of Food Sciences, Vol. 41, No.1, (2008), pp.:71-81

9. Singh, Baljeet, and Yogesh C. Joshi. "Increased potato productivity, its consequences and sustainable production." International Journal of Business and General Management, 5 (3), 6580 (2016).

10. Maezawa S, Akimoto $K$ Characteristics of electrical conductivity of low-temperature sensitive vegetables. Res Bull Fac AgrGifu Univ, Japan 61:81-86

11. Mudgett RE, “Electrical properties of foods. In: Rao MA, RizviSSH (eds) Engineering properties of foods”. Marcel Dekker, New York, (1996) ,pp 329-390 
12. O. P. Chauhanet al., 'Non-destructive Quality Monitoring of Fresh Fruits and Vegetables', Defense Life Science Journal, Vol. 2, No. 2, (2017), pp. 103-110.

13. Sheeja, P.S. \& Ajay Gokul,.A.J., "Nondestructive quality evaluation for fruits and vegetables", International Journal of Modern Trends Engineering Research., Vol.3, (2016), pp.2349-9745. 